\title{
Multiple glycerol shocks increase the calcium phosphate transfection of non-synchronized $\mathrm{CHO}$ cells
}

\author{
Frederic Grosjean • Martin Bertschinger • \\ David L. Hacker · Florian M. Wurm
}

Received: 12 July 2006/ Accepted: 14 July 2006/Published online: 29 September 2006

(C) Springer Science+Business Media B.V. 2006

\begin{abstract}
The exposure of CHO DG44 cells to an osmotic shock, after DNA uptake, results in a cellular volume decrease of approx. $55 \%$. Repetitive osmotic shocks targeted different subpopulations of cells as was demonstrated using two different fluorescent reporter genes. Also the exposure of a calcium phosphate-DNA coprecipitate to high osmolarity in vitro caused the release of the DNA from the precipitate. The results demonstrate the importance of the osmotic shock on the efficient delivery of plasmid DNA to the nucleus of CHO cells following calcium phosphate-mediated transfection.
\end{abstract}

Keywords Calcium phosphate $\cdot$ Cellular volume decrease - Glycerol shock - Osmotic effect · Plasmid release $\cdot$ Transfection

F. Grosjean $(\bowtie)$

Institute of Biochemistry, Chemin des Boveresses 155, 1066 Epalinges, Switzerland

e-mail: Frederic.Grosjean@unil.ch

M. Bertschinger

Glenmark Pharmaceuticals SA.,

Chemin de la Combeta 5,

2300 La Chaux-de-Fonds, Switzerland

D. L. Hacker · F. M. Wurm

Laboratory of Cellular Biotechnology,

École Polytechnique Fédérale de Lausanne (EPFL),

1015 Lausanne, Switzerland

\section{Introduction}

Calcium phosphate-DNA coprecipitation ( $\mathrm{CaPi}$ transfection) is one of the most widely used methods for the transfection of cultivated mammalian cells (Graham and Van Der Eb 1973). DNA is first complexed with calcium and phosphate to form small insoluble particles that are endocytosed by cells (Loyter et al. 1982a; Orrantia and Chang 1990). The DNA is then released into the cytoplasm by an unknown mechanism and diffuses within the cell, probably as a complex with calcium phosphate (Loyter et al. 1982b). After release in the cytoplasm the DNA is exposed to cellular DNases but it may be protected in part from digestion by association with calcium phosphate (Loyter et al. 1982b). Less than $10 \%$ of internalized plasmid DNA eventually enters the nucleus as the majority of the DNA is recovered from the cytosol as fragments less than $100 \mathrm{bp}$ in length (Orrantia and Chang 1990). The half-life of plasmid DNA in the cytoplasm is approximately 50-90 min (Lechardeur et al. 1999). Entry of the DNA into the nucleus may be restricted to the time of nuclear membrane breakdown during mitosis (Brunner et al. 2000; Mortimer et al. 1999; Wilke et al. 1996), and it has been shown that CaPi transfection of CHO cells is cell cycle-dependant (Grosjean et al. 2002). Clearly, the variation of reporter gene expression observed in individual cells after 
CaPi transfection is not the result of the inability of DNA to enter cells, as most cells take up plasmid DNA during this process (Batard et al. 2001). Thus, the low diffusion rate of the coprecipitate complexes from the cytoplasm to the nucleus with the accompanying exposure to nucleases and the subsequent entry of the complexes into the nucleus are the most significant barriers to gene transfer by CaPi transfection (Capecchi 1980; Dowty et al. 1995).

Several physical parameters also play a role in efficient $\mathrm{CaPi}$ transfection. The incubation time for formation of the calcium phosphate-DNA coprecipitate, the $\mathrm{pH}$ of the calcium and phosphate solutions, the amount of serum in the culture medium, and the calcium phosphate to plasmid ratio are critical for efficient DNA uptake by cells (Jordan et al. 1996; O'Mahoney and Adams 1994; Wake et al. 1984). It is not the concentration of plasmid DNA on the cell surface that affects the level of plasmid uptake, but more likely the morphology of the calcium phosphateDNA coprecipitate. Precipitate formation in the presence of a high concentration of plasmid DNA results in inefficient coprecipitate uptake (Loyter et al. 1982b).

In this report the CaPi transfection of nonsynchronized $\mathrm{CHO}$ cells was investigated. It was shown that an osmotic shock performed at the end of the transfection process resulted in a significant cellular volume decrease and an increase in transient reporter protein expression. The timing and the number of osmotic shock treatments were also found to be important parameters for increasing the overall transfection efficiency in non-synchronized cells. Finally, a possible role for the osmotic shock on plasmid DNA release from the transfection complex was investigated in vitro. The results of these experiments demonstrated the importance of the treatment to the CaPi transfection of $\mathrm{CHO}$ cells.

\section{Materials and methods}

Cell culture

CHO DG44 cells were maintained as attached cells in DMEM/F12 medium (Gibco, Edinburgh,
Scotland) supplemented with $2 \%(\mathrm{v} / \mathrm{v})$ fetal calf serum (FCS) (SeraTech, Germany) in T-75 flasks at $37^{\circ} \mathrm{C}$ in a $5 \% \quad \mathrm{CO}_{2}$ atmosphere with $90 \%$ humidity. Cells were passed every 2-3 days after reaching a confluency of $80 \%$.

\section{Determination of packed cell volume}

Cells detached from plates using trypsin were centrifuged and resuspended in DMEM/F12 supplemented with $2 \%(\mathrm{v} / \mathrm{v}) \mathrm{FCS}$, or in $10 \times \mathrm{PBS}$, $10 \%(\mathrm{v} / \mathrm{v})$ glycerol in PBS, or $1 \mathrm{M} \mathrm{NaCl}$. For each condition, $1 \mathrm{ml}$ cell suspension was transferred to a mini-PCV tube (TPP, Trasadingen, Switzerland) and centrifuged in an Eppendorf 5417C microcentrifuge for $1 \mathrm{~min}$ at 5,000 rpm. The volume of the packed cells (PCV) in the graduated capillary was reported as the \% PCV.

\section{Transfection}

Cells were transfected using a slightly modified CaPi method (Jordan et al. 1996). At 4 h prior to transfection, cells were seeded in a volume of $1 \mathrm{ml}$ at a density of $6.5 \times 10^{5}$ cells $/ \mathrm{ml}$ in 12 -well plates. Two-thirds of the culture medium was removed just before the addition to each well of $100 \mu \mathrm{l}$ of the transfection solution containing $125 \mathrm{mM} \mathrm{CaCl}, 0.7 \mathrm{mM} \mathrm{PO}_{4}^{3-}$, and $2.5 \mu \mathrm{g}$ of either pEGFP-N1 or pDsRedExpress (Clontech, Palo Alto, CA). Cells were incubated at $37^{\circ} \mathrm{C}$ for $1 \mathrm{~h}$ before exchanging the transfection medium with a solution of high osmolarity as indicated in the text. After $1 \mathrm{~min}$ the solution was removed and DMEM/F12 containing 2\% FCS was added. Occasionally, additional glycerol shocks were performed as indicated in the text. To remove the residual CaPi-DNA coprecipitate from cells after the osmotic shock, the cells were washed once with a $5 \mathrm{mM}$ EGTA in PBS. The solution was removed after 10-15 s, and the cells were washed once with PBS before addition of fresh DMEM/ F12 with 2\% FCS.

\section{Reporter protein quantification}

The expression of enhanced green fluorescent protein (EGFP) and DsRed protein were quantified at $48 \mathrm{~h}$ after transfection using a Cytofluor 
Series 4000 plate reader (PerSeptive Biosystems, Framingham, MA). Reporter protein expression was also monitored by fluorescence microscopy (Axiovert 200M, Zeiss, Feldbach, Switzerland). Excitation and emission wavelengths were selected with Zeiss filter set \#17 (excitation: BP 485/20 nm, beamsplitter: FT $510 \mathrm{~nm}$; emission: BP 515-565 nm) for detection of EGFP and filter set \#14 (excitation: BP 510-560 nm; beamsplitter: FT $580 \mathrm{~nm}$; emission: LP $590 \mathrm{~nm}$ ) for detection of DsRed.

Plasmid release assay

Plasmid DNA (2.5 $\mu \mathrm{g})$ was first mixed with $125 \mathrm{mM} \mathrm{CaCl}_{2}$ and then phosphate was added to $0.7 \mathrm{mM}$ in a final volume of $100 \mu \mathrm{l}$. The solution was allowed to stand for $1 \mathrm{~min}$ and then diluted with either 10 volumes of DMEM/F12 with $2 \%$ $(\mathrm{v} / \mathrm{v})$ FCS or varying concentrations of TBS, $\mathrm{NaCl}$, or glycerol in TBS as indicated in the text. After a $1 \mathrm{~min}$ incubation, the mixture was centrifuged at $13,000 \mathrm{rpm}$ for $2 \mathrm{~min}$ to pellet $\mathrm{CaPi}-$ DNA particles. The free plasmid DNA in the supernatant was precipitated with isopropanol. After centrifugation the pellet was washed once with $70 \%(\mathrm{v} / \mathrm{v})$ ethanol, resuspended in TE, and analyzed by agarose gel electrophoresis. As a positive control, the same amount of DNA as in the CaPi precipitation was mixed with $150 \mathrm{mM}$ $\mathrm{NaCl}$ and then diluted with $150 \mathrm{mM} \mathrm{NaCl}$ prior to centrifugation as described above.

\section{Results}

For the CaPi transfection of $\mathrm{CHO}$ cells, applying an osmotic shock to the cells after DNA delivery enhances transient recombinant protein expression but not DNA uptake by the cells (Batard et al. 2001). To determine the effect of short-term exposure to high osmolarity, CHO DG44 cells were detached from plates and suspended in either DMEM/F12 with $2 \%$ (v/v) FCS, $10 \%$ (v/v) glycerol in PBS, $1 \mathrm{M} \mathrm{NaCl}$, or $10 \times$ PBS. The cells were immediately centrifuged for $1 \mathrm{~min}$ in a miniPCV tube to determine the volumetric change of the cells. A $55 \%$ decrease in cell volume was observed as the result of exposure to $10 \%(\mathrm{v} / \mathrm{v})$

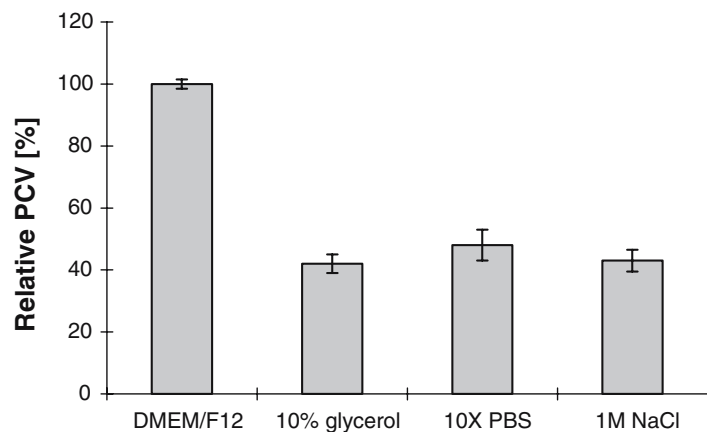

Fig. 1 Effect of high osmolarity on cell volume. The approximate volume of CHO DG44 cells was determined using mini-PCV tubes following exposure to the conditions indicated for $1 \mathrm{~min}$. As a control the cells were suspended in DMEM/F12 with $2 \%$ FCS prior to the PCV determination. Each bar represents the average of three independent experiments

glycerol in PBS (Fig. 1). No further volume decrease occurred when higher glycerol concentrations (up to $20 \% \mathrm{v} / \mathrm{v}$ ) were used (data not shown). Glycerol concentrations higher than $15 \%$ did result in a reduction in cell viability (data not shown). The cell volume was also reduced by $50-55 \%$ following a $1 \mathrm{~min}$ exposure to either $10 \times$ PBS or $1 \mathrm{M} \mathrm{NaCl}$ (Fig. 1). The osmolarity of each solution is shown in Table 1.

To determine if the osmotic shock after $\mathrm{CaPi}$ transfection could be performed with solutions other than $10 \%$ (v/v) glycerol, CHO DG44 cells were transfected with pEGFP-N1, and the cells were treated post-transfection with either $10 \%$ glycerol, 10× PBS, or $1 \mathrm{M} \mathrm{NaCl}$ for $1 \mathrm{~min}$. Reporter gene expression was assessed $48 \mathrm{~h}$ after the osmotic shock. Treatment with either $1 \mathrm{M}$ $\mathrm{NaCl}$ or $10 \times$ PBS resulted in higher EGFP expression than was observed following treatment with $10 \%$ glycerol (Fig. 2). This indicated that glycerol itself was not the effector of gene transfer. However, osmotic effects alone may not be

Table 1 Osmolarity of solution used in this work

\begin{tabular}{ll}
\hline & $\begin{array}{l}\text { Osmolarity } \\
(\mathrm{mOsm})\end{array}$ \\
\hline $\mathrm{DMEM} / \mathrm{F} 12$ & 330 \\
$10 \%(\mathrm{v} / \mathrm{v})$ glycerol & 1,980 \\
$10 \times \mathrm{PBS}$ & 2,690 \\
$1 \mathrm{M} \mathrm{NaCl}$ & 2,000 \\
\hline
\end{tabular}




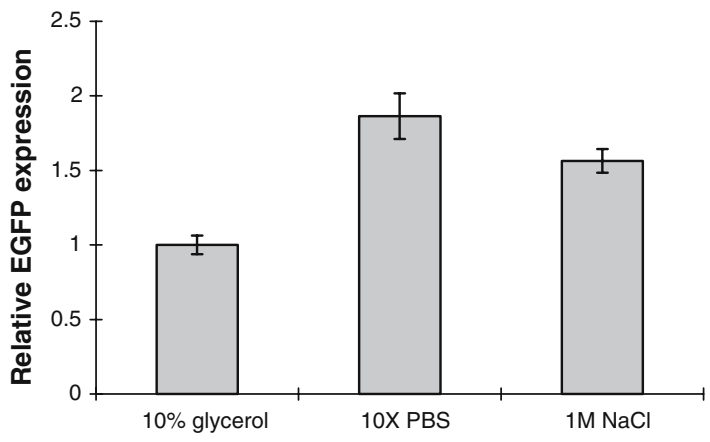

Fig. 2 Effect of high osmolarity on CaPi-mediated transfection of CHO DG44 cells. Cells were transfected with pEGFP-N1. After removal of the CaPi precipitate, the cells were treated for $1 \mathrm{~min}$ with $10 \%(\mathrm{v} / \mathrm{v})$ glycerol, $10 \times$ PBS, or $1 \mathrm{M} \mathrm{NaCl}$. EGFP-specific fluorescence was measured at $48 \mathrm{~h}$ post-transfection. Each bar represents the average of five independent transfections

sufficient for efficient gene transfer into $\mathrm{CHO}$ DG44 cells by $\mathrm{CaPi}$ transfection since exposure to $5 \%(\mathrm{v} / \mathrm{v})$ glycerol decreased the cell volume to the same extent as $10 \%$ glycerol but resulted in five times less reporter gene expression than observed following treatment with $10 \%$ glycerol (data not shown).

To determine the optimum time after transfection for application of the osmotic shock, $\mathrm{CHO}$ DG44 cells were transfected with pEGFP-N1 and treated with $10 \%$ glycerol at different times after removal of the $\mathrm{CaPi}$ precipitate. The highest

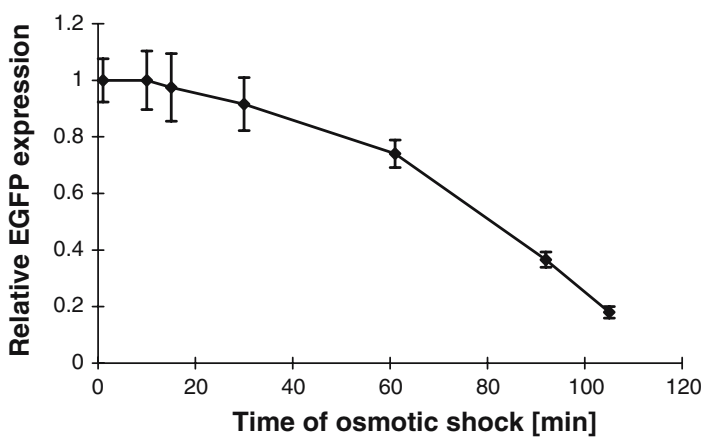

Fig. 3 Effect of time on the efficacy of the osmotic shock treatment after CaPi-mediated transfection of CHO DG44 cells. Cells were transfected with pEGFP-N1. The CaPiDNA complexes were removed with an EGTA wash step. Cells were subsequently treated with a $10 \%$ (v/v) glycerol shock at various times after removal of the $\mathrm{CaPi}$ precipitate. EGFP-specific fluorescence was determined $48 \mathrm{~h}$ after transfection. Each time point represents the average of five independent transfections levels of EGFP expression were observed when the osmotic shock was delivered during the first $30 \mathrm{~min}$ after transfection (Fig. 3). Delaying the glycerol shock to $60 \mathrm{~min}$ post-transfection resulted in a $20 \%$ reduction in EGFP expression relative to the highest levels of EGFP expression observed (Fig. 3). Further decreases in reporter protein expression were seen following delivery of the osmotic shock at 90-105 min post-transfection (Fig. 3). The results support previous observations that the half-life of internalized plasmid DNA in mammalian cells is approximately 50-90 min (Lechardeur et al. 1999).

In an attempt to improve the CaPi transfection of $\mathrm{CHO}$ cells, cells transfected with pEGFP-N1 were exposed to 1-4 osmotic shocks with $10 \%$ glycerol after removal of the CaPi precipitate. The treatments were spaced every 10-20 min, with the first one given right after the removal of the CaPi precipitate. The second and third osmotic shocks, but not the fourth, resulted in increases in EGFP expression compared to the control transfection with one osmotic shock treatment (Fig. 4). As the number of treatments increased, the number of EGFP-positive cells in the transfected population also increased (data not shown). Parallel transfections were performed with treatments with PBS every 15 min after the

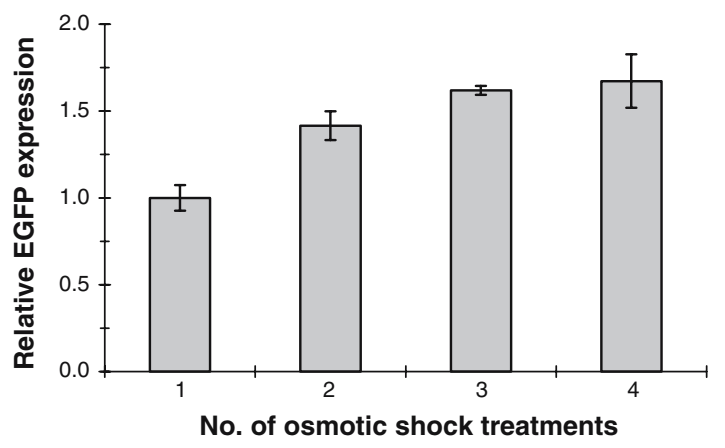

Fig. 4 The effect of multiple osmotic shocks after CaPimediated transfection of CHO DG44 cells. Cells were transfected with pEGFP-N1. After $1 \mathrm{~h}$ the CaPi precipitate was removed by washing the cells with EGTA immediately after the first osmotic shock with $10 \%$ glycerol in PBS. The control culture (CTRL) received only one glycerol treatment. The second, third, and fourth treatments were applied 20,35, and $45 \mathrm{~min}$ after the first one, respectively. EGFP-specific fluorescence was measured $48 \mathrm{~h}$ after transfection. Each bar represents the average of five independent transfections 
initial glycerol shock. The additional treatments with PBS did not result in an increase in EGFP expression (data not shown).

To demonstrate that the additional osmotic shocks increased reporter protein expression in cells that did not express the reporter protein after the first treatment, cells were transfected twice with two different reporter genes. Initially, cells were transfected with pEGFP-N1. An hour after the addition of the first transfection complex, an osmotic shock was performed before the cells were allowed to incubate for $1 \mathrm{~h}$. Then a second transfection was performed with pDsRed Express, and the cells were incubated for $1 \mathrm{~h}$ in the presence of the second transfection complex before another osmotic shock was performed. This time window ensured that no cells would proceed through a complete cell cycle between the two transfections and that none of the remaining intracellular plasmid from the first transfection could efficiently diffuse to the nucleus during the osmotic shock of the second transfection. After each transfection, an EGTA wash step was performed to remove remaining extracellular transfection complexes. Microscopic observation of the transfected cells revealed two distinct populations that either expressed EGFP or DsRed (Fig. 5). Very few cells expressed both proteins (Fig. 5). In contrast, when the two plasmids were transfected simultaneously, all the transfected cells expressed both reporter proteins (data not shown). These results indicated that it was not possible to target the same cells with two different transfections performed within $1 \mathrm{~h}$ of each other.

It is not known how the osmotic shock applied after CaPi-mediated transfection of $\mathrm{CHO}$ DG44 cells affects the internalized plasmid DNA. One possibility is that it causes the disruption of the CaPi-DNA particles, resulting in enhanced plasmid DNA delivery to the nucleus. To test this hypothesis, CaPi-DNA particles were exposed to increasing concentrations of TBS, $\mathrm{NaCl}$, or glycerol and the mixtures were centrifuged to pellet any remaining particles. The DNA liberated from particles was recovered from the supernatant and analyzed by agarose gel electrophoresis. In the presence of $1 \times$ TBS, $0.15 \mathrm{M} \mathrm{NaCl}$, or $5 \%(\mathrm{v} / \mathrm{v})$ glycerol, little DNA was released from the preformed particles (Fig. 6). As the osmolarity was increased, however, the amount of DNA released from the particles also increased (Fig. 6). It is possible that destabilization of internalized CaPi-DNA particles may also occur as the result of the osmotic shock applied after transfection, releasing plasmid DNA from CaPi in the cytosol or nucleus.
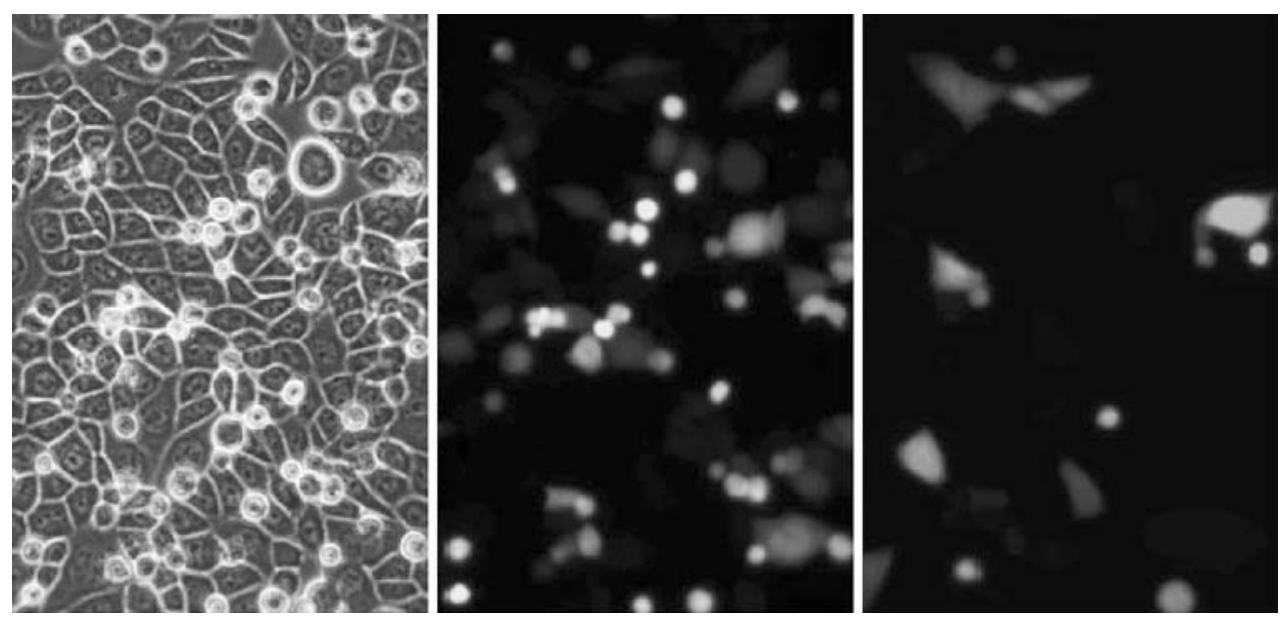

Fig. 5 Double transfection of CHO DG44 cells with pEGFP-N1 and pDsRedExpress. The transfected cells were photographed under visible light (left panel), UV light with filters set for excitation and detection of EGFP (middle panel), or UV light with filters set for excitation and detection of DsRed (right panel) 


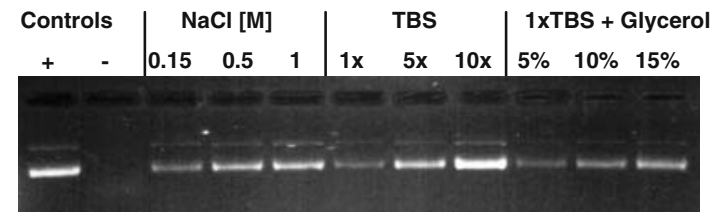

Fig. 6 Effect of high osmolarity on the stability of $\mathrm{CaPi}-$ DNA complexes in vitro. $\mathrm{CaPi}-\mathrm{DNA}$ complexes were formed by mixing plasmid DNA in $125 \mathrm{mM} \mathrm{CaCl}_{2}$ (final concentration) and $0.7 \mathrm{mM}$ phosphate. The complexes were diluted with 10 volumes of the indicated solutions. As a positive control (+) the DNA was mixed with $150 \mathrm{mM}$ $\mathrm{NaCl}$ instead of calcium and phosphate and then diluted in 10 volumes of $150 \mathrm{mM} \mathrm{NaCl}$. For the negative control (-) CaPi-DNA complexes were diluted with 10 volumes of DMEM/F12 medium containing $2 \%(\mathrm{v} / \mathrm{v})$ FCS. After $1 \mathrm{~min}$ at room temperature the mixtures were centrifuged and DNA was recovered from the supernatant by isopropanol precipitation. The DNA was then analyzed by agarose gel electrophoresis

\section{Discussion}

For efficient transfection of $\mathrm{CHO}$ cells with $\mathrm{CaPi}$, an osmotic shock after exposure of cells to the CaPi-DNA precipitate is necessary. As shown in this report, agents besides glycerol can be used for this step. To be most effective the osmolarity change must be performed within about $30 \mathrm{~min}$ of the removal of the CaPi-DNA precipitate from the cells. In addition, multiple osmotic shocks spaced 10-20 min apart were shown to enhance the transfection efficiency by increasing the number of cells expressing the reporter protein. The additional osmotic shocks were performed within $1 \mathrm{~h}$ of the removal of the CaPi-DNA complexes.

The osmolarity change after transfection does not result in the entry of additional plasmid DNA into cells. Instead, it affects plasmid DNA that has already been endocytosed (Batard et al. 2001). Therefore, it may play a role in the plasmid's endosomal escape, nuclear uptake, or release from CaPi particles. Conceivably, more than one of these steps in the transfection process may be affected by the osmolarity change. The osmotic shock may destabilize the endosomal membrane resulting in the release of the CaPi-DNA complexes within the intracellular environment (Batard et al. 2001; Sabelnikov 1994). In this report it was demonstrated that high osmolarity disrupts $\mathrm{CaPi}$-DNA complexes in vitro. This effect may also be important within transfected cells since the intracellular osmolarity increases as the result of the osmotic shock treatment. Since the mechanism of CaPi-DNA complex disassociation is not understood, it is not known at what stage of the transfection process the particle disruption occurs.

By using two different reporter plasmids for two sequential transfections of the same cell population it was demonstrated that two different subpopulations of cells were targets of DNA uptake. Since the cell cycle is important for the $\mathrm{CaPi}$ transfection of $\mathrm{CHO}$ cells (Grosjean et al. 2002) additional osmotic shocks are advised for non-synchronized $\mathrm{CHO}$ cells to target a greater number of cells. Here we showed, using nonsynchronized cells, that different subpopulations were competent for $\mathrm{CaPi}$ transfection at different times after the cells were plated. In addition, the second transfection and osmotic shock were completed after most of the pEGFP-N1 from the first transfection had either reached the nucleus or else had been degraded. If the pEGFP-N1 from the first transfection had remained in the cytoplasm until the time of the second osmotic shock, a significant number of cells expressing both EGFP and DsRed would have been observed. Thus, these results support the conclusion that there is only a short time after transfection in which the intracellular plasmid DNA remains functional for transport to the nucleus and for subsequent gene expression.

Acknowledgments The authors would like to thank ZLB Bioplasma AG in Bern, Switzerland for financial support of this work.

\section{References}

Batard P, Jordan M, Wurm F (2001) Transfer of high copy number plasmid into mammalian cells by calcium phosphate transfection. Gene 270:61-68

Brunner S, Sauer T, Carotta S, Cotten M, Saltik M, Wagner E (2000) Cell cycle dependence of gene transfer by lipoplex, polyplex and recombinant adenovirus. Gene Ther 7:401-407

Capecchi MR (1980) High efficiency transformation by direct microinjection of DNA into cultured mammalian cells. Cell 22:479-488 
Dowty ME, Williams P, Zhang G, Hagstrom JE, Wolff JA (1995) Plasmid DNA entry into postmitotic nuclei of primary rat myotubes. Proc Natl Acad Sci USA 92:4572-4576

Graham FL, Van Der Eb AJ (1973) A new technique for the assay of infectivity of human adenovirus 5 DNA. Virology 52:456-467

Grosjean F, Batard P, Jordan M, Wurm F (2002) S-phase synchronized $\mathrm{CHO}$ cells show elevated transfection efficiency using CaPi. Cytotechnology 38(1-3):57-62

Jordan M, Schallhorn A, Wurm F (1996) Transfecting mammalian cells: optimization of critical parameters affecting calcium-phosphate precipitate formation. Nucl Acids Res 24:596-601

Lechardeur D, Sohn KJ, Haardt M, Joshi PB, Monck M, Graham RW, Beatty B, Squire J, O'Brodovich H, Lukacs GL (1999) Metabolic instability of plasmid DNA in the cytosol: a potential barrier to gene transfer. Gene Ther 6:482-497

Loyter A, Scangos G, Juricek D, Keene D, Ruddle FH (1982a) Mechanisms of DNA entry into mammalian cells. II. Phagocytosis of calcium phosphate DNA co-precipitate visualized by electron microscopy. Exp Cell Res 139:223-234

Loyter A, Scangos G, Ruddle FH (1982b) Mechanisms of DNA uptake by mammalian cells: fate of exogenously added DNA monitored by the use of fluorescent dyes. Proc Natl Acad Sci USA 79:422-426
Mortimer I, Tam P, MacLachlan I, Graham RW, Saravolac EG, Joshi PB (1999) Cationic lipid-mediated transfection of cells in culture requires mitotic activity. Gene Ther 6:403-411

O'Mahoney JV, Adams TE (1994) Optimization of experimental variables influencing reporter gene expression in hepatoma cells following calcium phosphate transfection. DNA Cell Biol 13:1227-1232

Orrantia E, Chang PL (1990) Intracellular distribution of DNA internalized through calcium phosphate precipitation. Exp Cell Res 190:170-174

Sabelnikov AG (1994) Nucleic acid transfer through cell membranes: towards the underlying mechanisms. Prog Biophys Mol Biol 62:119-152

Wake CT, Gudewicz T, Porter T, White A, Wilson JH (1984) How damaged is the biologically active subpopulation of transfected DNA? Mol Cell Biol 4:387398

Wilke M, Fortunati E, Van Den Broek M, Hoogeveen AT, Scholte BJ (1996) Efficacy of a peptide-based gene delivery system depends on mitotic activity. Gene Ther 3:1133-1142 